\title{
Promoção da saúde no processo de democratização brasileiro: biopolíticas e constituição de sujeitos da saúde
}

\author{
Ana Maria Pereira Lopes \\ Universidade do Sul de Santa Catarina, Palhoça, SC, Brasil
}

\begin{abstract}
Resumo
Em um estudo sobre promoção da saúde como uma biopolítica, objetivou-se analisar como práticas biopolíticas, no processo de democratização brasileira nos anos de 1980 e 1990, constituem sujeitos, por meio da objetivação pelos discursos e normas. A pesquisa teve como fonte documentos que instalam a promoção da saúde, considerando-os como monumentos, intencionais, com efeitos na objetivação de sujeitos. A promoção da saúde é considerada como prática histórica, datada e como dispositivo estratégico de governamentalidade. Organizando-se os documentos em subarquivos, a análise foi conduzida pela problematização - arqueológica e genealógica - de Michel Foucault. A promoção da saúde é articulada estrategicamente com o discurso da saúde ampliada e relações econômicas desenvolvimentistas. Em meio ao governo médico da vida ocorre a objetivação de sujeitos na relação com práticas de promoção da saúde, sobretudo na atenção básica, o que possibilita aportes para se problematizar a subjetividade nesses espaços.
\end{abstract}

Palavras-chave: promoção da saúde; biopolitica; constituição do sujeito; atenção básica.

\section{Health promotion in the Brazilian democratization process: biopolicies and constitution of health subjects}

\begin{abstract}
In a study on health promotion as a biopolicy, it was aimed to analyze how the biopolicy practices constitute subjects, in the Brazilian democratization process, in the 1980s and 1990, sthrough the objectivation by speeches and norms. The survey was based on documents that install health promotion, considering them as monuments, intentional ones, with effect on the objectification of the subjects. Health promotion was considered a historical practice, dated and as strategical device of governmentality. By organizing the documents in subfiles, the analysis was conducted by raising the issues - archeological and genealogical ones - by Michel Foucault. Health promotion is strategically articulated with extended health discourse and developmental economic relations. During the medical government of life, the objectivization of subjects in the relation with the practices of health promotion take place, specially in the primary care, what makes it possible to problematize the subjectivity in theses spaces.
\end{abstract}

Keywords: health promotion; biopolicy; subject constitution; primary care.

\section{Introdução}

Promoção da saúde foi um discurso instalado, muito recentemente, na segunda metade do século XX, no cenário das práticas sociais em saúde. Ela ampliou a ideia de cura ou de prevenção e tentou designar um tipo de comportamento individual e coletivo com novas possibilidades de manter a vida. É um termo articulado a um imperativo de saúde sobre os sujeitos, quando faz parte das relações sociais manter a saúde e condutas que potencializem a vida e seu pleno funcionamento. Sob a égide da promoção da saúde, sujeitos são conduzidos a práticas esportivas, hábitos alimentares saudáveis ou, ainda, que se desviem de situações que acarretem risco à plena condição física ou mental. Os discursos acerca dessa oferta de saúde à população não se caracterizaram apenas por pressupostos biológicos de cuidado, mas se deslocaram do eixo das práticas médico-curativas, hospitalares, para aquelas denominadas de saúde ampliada.

A ideia de promoção da saúde advém de um modo de funcionamento da sociedade contemporânea, que nos séculos XIX e XX e, sobretudo, nas últimas décadas do século XX, teve o Estado como protagonista na instalação de políticas sociais e públicas na direção de uma revisão das práticas de saúde centradas em adoeci-

\footnotetext{
^Endereço para correspondência: Universidade do Sul de Santa Catarina, Unidade Pedra Branca. Av. Pedra Branca, 25, Cidade Universitária. Palhoça, SC Brasil. CEP: 99999270.E-mail: anaralina@gmail.com

Os dados completos da autora encontram-se ao final do artigo.
}

mentos. Nesse processo, conferências internacionais de saúde, como a de Alma Ata, em 1978, e a de Promoção da saúde, em 1986, foram acontecimentos importantes no cenário mundial da saúde.

Especificamente no Brasil, a VIII Conferência Nacional de Saúde foi o acontecimento mais importante para a consecução de uma saúde pública. Esse conjunto de direcionamentos internacionais e nacionais possibilitou a ideia de Estado como organizador da atenção em saúde, por meio do Sistema Único de Saúde (SUS), que teve sua instalação iniciada em 1990, após a Constituição Federal de 1988 (BRASIL, 1988), seguida por meio de um conjunto de legislações e portarias ministeriais que visavam dar operacionalidade a esse novo desenho do setor saúde.

Em 2006, foi instalada a Política Nacional de Promoção da saúde (PNPS). Com ela ficou estabelecido que "as intervenções em saúde ampliem seu escopo [...], que operem sobre os efeitos do adoecer e aqueles que visem ao espaço para além dos muros das unidades de saúde e do sistema de saúde" (BRASIL, 2006a).

Paralelamente à PNPS, em 2006, foi instalada a Política Nacional de Atenção Básica (PNAB) (BRASIL, 2006b), com alcance de status de uma política nacional para a atenção primária. A PNAB estabelece a Estratégia de Saúde da Família (ESF), que já vinha sendo operacionalizada ao longo da década de 1990. Com a ESF, a atenção primária, ou atenção básica, passou a ser lócus 
estratégico para a ampliação do escopo do setor saúde sobre a vida das pessoas, para além de haver algum indicador de doença. Ou seja, a atenção básica se coloca como lugar possível para a promoção da saúde.

A atenção básica, que ocorre nas chamadas Unidades Básicas de Saúde (UBS), já alcançava cobertura de mais de 50\% da população em 2010. E em 2006 passou a ser responsável por ações individuais e coletivas, buscando abranger:

Promoção e a proteção da saúde, a prevenção de agravos, o diagnóstico, o tratamento, a reabilitação, redução de danos e a manutenção da saúde com o objetivo de desenvolver uma atenção integral que impacte na situação de saúde e autonomia das pessoas e nos determinantes e condicionantes de saúde das coletividades (BRASIL, 2006b).

A PNPS pode ser considerada um acontecimento em saúde pública no Brasil. Tal modelo ocorreu a partir da transição política do Estado ditatorial ao democrático, iniciada na década de 1980, que buscava estabilidade das relações sociais, por meio de políticas sociais, sem as quais não ocorreria a institucionalização democrática (LUZ, 2000). Com o SUS, ocorreu uma assunção do Estado com relação ao acesso à saúde, garantido anos antes na Constituição Federal de 1988. Nessa mesma esteira ocorreu também a assunção de dispositivos constitucionais, por meio de políticas intersetoriais à saúde, como a obrigação de erradicar a pobreza, marginalização e redução das desigualdades sociais e regionais, vislumbrando a consecução de um Estado Democrático de Direito e de sua ação de constituição de sujeitos por meio de suas práticas sociais estatais.

O Estado e suas práticas de saúde são tomados aqui como objeto de análise, com base no pensamento de Michel Foucault. Entende-se que os avanços do setor saúde envolvem processos de objetivação pelos discursos e pelas normas que incidem sobre os sujeitos. Tal objetivação ocorre na perspectiva do biopoder, como preocupação moderna com a vida e sua manutenção e na perspectiva da biopolítica, ou sobre o corpo coletivo das populações (FOUCAULT, 1988a).

Foucault (1988a) mostra que nos séculos XVII e XVIII a vida foi tomada como objeto e alvo político. O poder disciplinar desenvolveu-se no início do século XVII com a anátomo-política - saber que é relacionado à potencialização do corpo, disciplina-mecanismo. Deu-se primeiramente no conhecimento do corpo como máquina: "no seu adestramento, na ampliação de suas aptidões, na extorsão de suas forças, no crescimento paralelo de sua utilidade e docilidade, na sua integração em sistema de controle eficaz e econômico" (FOUCAULT, 1988a, p. 151). Ou seja, para os novos contextos produtivos concorria o modo de organização das instituições e das práticas sociais a elas relacionadas: o poder disciplinar almejava o corpo como um aparelho eficiente.

A biopolítica formou-se na segunda metade do século XVIII e foi designada de disciplina bloco, corpo coletivo das populações, com centramento "no corpo transpassado pela mecânica do ser vivo e como suporte dos processos biológicos, sendo seus alvos de interesse: taxas de natalidade e de procriação, saúde pública, demografia como uma ciência biopolítica, estatísticas, em direção à saúde de seu corpo coletivo" (FOUCAULT, 1988a, p. 151). Foucault (1988a) também mostra com as noções de biopoder e biopolíticas, por meio de sistemas de vigilância hierárquicos, combinados com sanções normalizadoras e técnicas de exame, que as disciplinas alcançam controle individualizado do sujeito.

Com as noções de biopoder e biopolíticas, há uma mudança definitiva da consideração da centralidade do Estado na manutenção da vida como uma razão de Estado. A ameaça dos adoecimentos levou a circunscrição de sujeitos a normas e a um poder médico sem precedentes. O corpo, que antes era individual, é cada vez mais coletivizado. A medicina passa a ocupar funções normalizadoras que ultrapassam a existência dos doentes e as demandas do doente. Como diz o próprio Foucault (2011, p. 384): "Desde o século XVIII, a medicina não cessou de se ocupar do que não lhe diz respeito, ou seja, do que não se refere aos diferentes aspectos dos doentes e das doenças". Essa colocação da medicina na vida dos sujeitos diz respeito a procedimentos de normalização, comparação, divisão, classificação e demarcação dos sujeitos com relação à média, à marcação destes por meio de diagnósticos e o encaminhamento para correções.

Por meio das biopolíticas, ou poder sobre os corpos de modo coletivo, por meio do governo sobre a vida é possível pensar a objetivação dos sujeitos a partir das práticas de promoção da saúde na atenção primária. A escalada do setor saúde, sobretudo no espaço da ESF, e promovida pela ideia de promoção de saúde, é aqui problematizada como um conjunto de ações operadas pela norma. Em meio a elas são buscadas visibilidades sobre os modos de objetivação presente nas práticas, ou, como diz Schramm (2006), identifica-se como saúde passa a ser um dever do cidadão e um direito do Estado, e não o contrário.

No presente estudo tem-se como objetivo analisar como práticas biopolíticas, no período da democratização brasileira, movidas pela ideia de promoção da saúde, objetivam sujeitos. Tal objetivo foi conduzido sob o pressuposto de que a promoção da saúde é um conjunto de discursos e práticas, ocorridas na atenção primária, sem a estreiteza do poder disciplinar, mas com enfrentamentos das normas oriundas do governo médico da vida. Ou seja, ainda que a promoção da saúde não seja conduzida diretamente por disciplinas e seja diferente das práticas hospitalares, tem a condução de poder medical.

\section{O percurso metodológico}

A fonte de dados foi um conjunto de documentos que instalaram a promoção da saúde no Brasil. Tais documentos foram identificados por meio de uma revisão bibliográfica sobre o tema. Na revisão, identificou-se a década de 1980 como período da instalação dos discursos de promoção da saúde, bem como foi possível a visibilidade sobre os principais documentos que circulavam e edificavam o discurso da promoção da saúde. Tais documentos foram organizados em arquivos de documentos 
primários, divididos em três subarquivos, de acordo com sua função em um dado conjunto de acontecimentos políticos, conforme quadro a seguir.

Figura 1 - Arquivo e subarquivos analisados tecimentos. Com Foucault (2008a), Le Goff (1990) e Albuquerque Júnior (1991), buscou-se uma relação da história das descontinuidades e rupturas.

Os documentos foram lidos, procurando-se séries analíticas, a partir de leituras transversais de seus conteúdos. Estas séries foram buscadas a partir das formações discursivas ou eixos de regularidade discursiva. Assim, a leitura transversal dos documentos tornou possível identificar seis séries analíticas que se mostravam regulares no sentido de um tipo de incidência de discursos e práticas sobre os sujeitos, quais sejam: "encampamento pelo Estado", "gestão em saúde", "condições de saúde e adoecimentos da população", "o desenFonte: elaborado pela autora, 2016.

Entre os documentos primários, há um primeiro subarquivo relativo à política de saúde no país no processo de democratização pós Constituição Federal de 1988 $(\mathrm{CF} / 88)$. A própria $\mathrm{CF} / 88$ é um desses documentos. $\mathrm{O}$ segundo subarquivo foi um tipo de achado, pois mostra um conjunto de iniciativas do Ministério da Saúde (MS), procurando dar institucionalidade à Promoção da Saúde, que seria instalada como uma política. No terceiro subarquivo, há documentos relativos à instalação da promoção da saúde, quando foram lançadas concomitantemente a Política Nacional de Promoção da Saúde e a Política Nacional de Atenção Básica, em 2006.

Os documentos foram analisados na perspectiva de arquivo, ou seja, considerando documentos como monumentos - método de Michel Foucault, que na perspectiva de arquivo são intencionais, com efeitos na objetivação e subjetivação de sujeitos, pois organizados com o objetivo de exercer algo sobre as pessoas (LEMOS et al., 2010), e então se referem à produção de saber e poder e com efeitos de subjetividade.

A subjetividade considerada no estudo não é relativa a um sujeito $a$ priori, da psicologia dos elementos, que já esteja pronto, mas considerando sujeito como resultado de práticas, de discursos e enunciações, que o atravessam. Tais documentos também foram considerados a partir de um tipo de pesquisa histórica crítica à história tradicional, que busca reconstituição da memória dos acon- volvimento econômico", "a participação social" e "saúde como estratégia para a democracia". Por meio dessa sequência de séries foi conduzida a análise dos subarquivos.

A promoção da saúde foi considerada como prática histórica, datada e como dispositivo estratégico de governamentalidade e foi analisada por meio da problematização - arqueológica e genealógica. A análise arqueológica se deu por meio da busca pela objetivação pelo discurso contido no documento, pela identificação das condições do surgimento daquele discurso, de suas modalidades enunciativas, dos aportes institucionais onde se instalavam, os jogos biopolíticos, ou forças que reunia buscando efeitos sobre os sujeitos (FOUCAULT, 2008a). A análise, que envolvia discursos, não se deu sobre a linguística, o conteúdo, ou modo como eram articuladas as palavras,

Figura 2 - Esquema do movimento do dispositivo, por meio de linhas de força

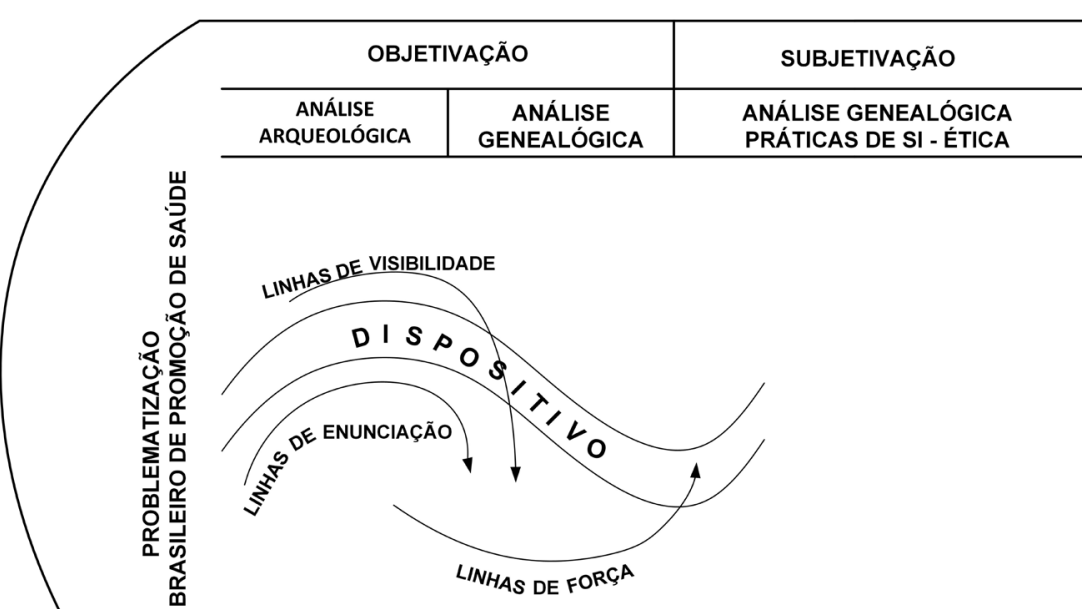

ARQUIVO - DOCUMENTO MONUMENTO 
o texto, mas sobre como esses documentos colocavam o aparecimento de um discurso. Além disso, na análise arqueológica ou genealógica se buscou relação com as linhas de visibilidade, enunciações, força e objetivações a partir de um dispositivo. Na Figura 2 é indicado o dispositivo como algo que aparece e se movimenta de acordo com forças discursivas, por meio de linhas de força.

$\mathrm{Na}$ análise genealógica buscou-se, a partir dos conteúdos dos documentos, a objetivação por meio de práticas incidentes nos corpos, a partir do poder das instituições e sua busca pelo poder produtivo de corpos e subjetividades. Assim como na arqueologia, buscou-se, na genealogia, a articulação com as linhas de um dispositivo, agora com as linhas de objetivação do sujeito por meio de práticas disciplinares.

A genealogia da ética, dimensão da análise na qual se buscaria, a partir do dispositivo da promoção da saúde, a dimensão da subjetivação, ou a resistência dos sujeitos em face da incidência dos discursos, as práticas de si, compreenderá outra publicação, focando-se aqui na objetivação pelos discursos e pelas práticas.

\section{Análise dos documentos}

\section{Processo de democratização: do discurso da saúde ampliada a um dispositivo de promoção da saúde}

Os três primeiros subarquivos dizem respeito a documentos relativos ao período de redemocratização do Brasil. O primeiro subarquivo foi o texto da VIII Conferência Nacional de Saúde (VIII CNS). Entre os enunciados desse documento, na série "encampamento pelo Estado", pode ser vista uma estatização da saúde, quando esta é designada como dever do Estado: "que começa pelo reconhecido direito do cidadão à saúde e o dever do Estado em prover os meios para isso" (BRASIL, 1986, p. 3). Esse enunciado é indicativo de um momento em que Estado e movimento social mantiveram discursos uníssonos, sendo difícil a quem acessa documentos do período identificar a origem do discurso. Por outro lado, ainda que se indicasse a responsabilidade do Estado, no mesmo texto da VIII CNS foi considerada possível a participação do setor privado, por meio de um enunciado que diz que serviços privados poderão prestar serviços à saúde, contudo sendo "coibidos os lucros abusivos" (BRASIL, 1986, p. 18). Ou seja, encontra-se demarcada na VIII Conferência uma coexistência de discursos, quando é indicado que se pode lucrar com a saúde, mas não se pode lucrar muito.

Os debates ocorreram de modo amplo na VIII CNS. Estado e movimento social com as mesmas discursividades, mas sob incidência de forças provenientes de um cenário econômico internacional. O SUS, regulamentado na Lei 8080/90, nasceu em meio aos seus inimigos: as práticas privadas, ou uma saúde dividida sob balizas do Estado (MATTOS, 2009). Ainda que resultado de um movimento social, o SUS também se estabeleceu em uma época em que a vida se tornara um problema político, para o qual deveria ser empreendida uma guerra por outros meios, tal qual mostrara Foucault (1999), o que será visto nas séries a seguir problematizadas, sobretudo no tocante a se ter uma saúde ampliada, alcançando, de fato, promoção da saúde.

Na série seguinte, com enunciados relativos à "gestão em saúde", pode ser vista ampliada a problematização antes iniciada. Na VIII CNS foi indicada a descentralização na gestão, mas a Lei 8080 (BRASIL, 1990a) não colocou a municipalidade como prioridade, por meio de financiamento. Desse modo, nos primeiros anos de SUS, municípios restringiram sua ação em negociar práticas de saúde com o setor privado, hospitais e transportes de pacientes para serviços diversos.

Procurando resolver o problema do financiamento, a Norma Operacional Básica de 1996 (NOB/96) fez a transferência de recursos do Piso de Atenção Básica (PAB), com acréscimos para aquele município que tivesse o então Programa de Saúde da Família (PSF) e o Programa de Agentes Comunitários de Saúde (PACS) - espaços profícuos para uma saúde ampliada. Contudo, imperava nesse período o discurso da atenção seletiva, pois muitos setores, inclusive da Organização Mundial de Saúde (OMS), indicavam que a atenção primária deveria ser seletiva a populações empobrecidas economicamente, consoante o Banco Interamericano de Desenvolvimento Regional (BIRD), que indicava a seletividade da atenção básica nos projetos que financiava. Havia aqui condições na gestão, que faziam desvalorizada a atenção básica que buscava se estabelecer, em um país com históricas faltas no setor saúde, o que acabou por tornar o terreno pouco propício para afirmar a atenção em saúde de modo ampliado. Desse modo, o campo da saúde se manteve investido em projetos que davam guaridas para o modelo hospitalar e ao mesmo tempo visavam ao futuro para planos de saúde privados.

Outra série organizada diz respeito à regularidade de enunciados relativos a "condições de saúde e adoecimentos da população". Na VIII CNS, o discurso oficial presidencial indicou: "Será deixado para trás o quadro desses Brasis: o forte, o doente, o fraco, o débil, o sadio. Construiremos, portanto, e devemos construir um só Brasil: o do povo com saúde, livre de todas as endemias" (BRASIL, 1986, p. 7). A própria $\mathrm{CF} / 88$ também indica a redução do risco de doença e de outros agravos; a Lei 8080/90 instalou a vigilância sanitária e epidemiológica, e tudo isso culminou, anos depois, com a NOB/96, na informatização dos dados em saúde, visando ao controle do adoecimento da população.

A contabilidade sobre adoecimentos é importante no nível de gestão, mas, nesse caso, também deixou visível a condução do sistema de saúde, que, como fora visto antes, com uma atenção básica frágil, apenas se manteve na perspectiva da contabilização de doenças. Tal condição deixava sem perspectiva uma saúde ampliada ou o que fosse a promoção da saúde, colocada pela Conferência de Otawa. Reafirmando esse modelo centrado na doença, a NOB/96 também indicou a prevenção ser prioritária quando indica: "enquadra-se, então, todo o espectro de ações compreendidas nos chamados níveis de atenção à 
saúde, representados pela promoção, pela proteção e pela recuperação, nos quais deve ser sempre priorizado o caráter preventivo" (BRASIL, 1996).

No contexto de contabilidade de adoecimentos na atenção básica, acessar o sistema de saúde público se dá com vistas à funcionalidade de sujeitos, que para tanto acessa medicamentos. A população, que tem um sistema público de saúde no qual se fazem presentes discursos da promoção da saúde, ainda assim acaba regularizada no seu adoecimento, individualmente ou em seu todo. A prática desse sistema se pauta na colocação de disciplinas e biopolíticas aplicadas a um corpo.

Os sistemas de informação podem ser vistos movimentando o dispositivo, pois foram instalados mecanismos que se tornaram funcionais no sentido de se tornar forte a epidemiologia enquanto saber. Por meio da estatística dos adoecimentos, a população, paulatinamente, tem um poder médico incidindo sobre ela, mesmo estando fora do hospital. O que viesse a ser promoção da saúde, uma vez atrelada à estatística, apenas seria um dispositivo normativo, muitas vezes ascendendo ao disciplinar, por meio de instruções do Estado sobre os "comportamentos saudáveis" dos sujeitos.

Outro conjunto de enunciados que aparecem nesse primeiro subarquivo é a "participação social". A VIII CNS que já ocorreu sob a égide da participação, com presença de mais de 4.000 pessoas, também instalou a ideia de controle social enquanto participação da sociedade no setor saúde, o que foi assumido pela $\mathrm{CF} / 88$ e instalado por meio da Lei 8142 (BRASIL, 1990b). Ao longo de tais documentos, a participação é enunciado bem presentificado.

O controle social, contudo, uma vez instalado, se burocratizou, pois passou a acontecer sob a égide de mecanismos estatais, levando a um distanciamento do movimento social onde teve origem. E, nessa esteira, a participação, de fato, passou a ser muito mais a criação de mecanismos de assentimento dos sujeitos às políticas, porque no contexto liberal, apolítico, a participação está voltada aos "fracassados", aqueles que não corresponderam a um modelo de produção e que não têm um plano de saúde. Por outro lado, a ideia de participação, quando bem procurada em espaços do sistema, é exígua. Inexiste em hospital ou ambulatório do SUS espaço para ser debatido o serviço oferecido. E, na atenção básica, espaço da saúde ampliada e da promoção da saúde, nesses primeiros tempos de SUS, a participação se instalou com dificuldades. Isto porque a atenção básica desqualificada, sem financiamento, seletiva no acesso, ou "coisa feita para pobres", não se coloca como espaço político afirmado.

A penúltima série desse mesmo subarquivo trata da preocupação com o "desenvolvimento econômico", quando o texto da VIII CNS diz que as políticas de saúde devem ocorrer por meio da "adoção de políticas sociais e econômicas que propiciem melhores condições de vida, sobretudo para os segmentos mais carentes da população" (BRASIL, 2006a, p. 14). A própria CF/88 atrela políticas sociais e economia, quando restam visíveis os limites para o setor saúde: a economia.
Na última série, há a visibilidade da "saúde como Estratégia para a democracia”. A própria arte do documento da VIII CNS indica, de modo lúdico, essa relação, alternando várias vezes as palavras "Saúde (e) Democracia (e) saúde". Nesse documento, há uma convocação ao Processo Constituinte, com enunciados chamando à discussão sobre problemáticas amplas do país, e não apenas relacionadas à saúde. Também há o discurso oficial presidencial que antecedia as deliberações da VIII CNS, indicando que "A democratização, portanto, do setor da saúde é compromisso de Governo" (BRASIL, 1986, p. 7). Ou seja, a ideia de democracia se misturava aos discursos sobre a saúde.

Nesse conjunto de documentos, a promoção da saúde ainda aparece sem grande delineamento em meio aos discursos da saúde ampliada, a qual era condizente com o período histórico - o da democratização, importante para que o Estado cumprisse sua função equilibradora de tensões e, na medida em que se fizessem necessárias respostas às demandas econômicas do país, sendo o Estado apenas o seu eixo equilibrante (FOUCAULT, 1992).

Ainda que houvesse uma fragilização da instalação da atenção primária, nela se concentra os discursos do que viria a ser a promoção da saúde. E, no contraponto, nela era visível o fortalecimento do discurso epidemiológico, o que afirmava, em ultima instância, o modelo hospitalar. Assim, nessa primeira etapa de problematização sobre o discurso no campo da saúde e suas decorrências práticas, a promoção da saúde é uma reedição da Medicina Social (séc. XVIII), ou organização da prática médica a resolver situações específicas de um país evidentemente articulado ao pensamento preventivista.

Assim, as transformações do setor saúde brasileiro reeditou o poder médico, mas também acompanhou o processo de transformação que esse mesmo poder atravessou, com direcionamentos para o ambiente das pessoas, numa perspectiva de uma medicina urbana, por meio da colocação de normas de convivência (FOUCAULT, 1992). Desse modo, o processo das mudanças no setor saúde tem também a marca das biopolíticas, que açambarca o modelo médico no que esse tem de controle sobre o corpo, para fora do hospital, no ambiente mais geral de vida dos sujeitos.

$\mathrm{Na}$ biopolítica, as normas passam a ser encaminhadoras das práticas, como dispositivos de governo, naturalizados e de difícil resistência por parte dos sujeitos e por meio de verdades cada vez mais totalizantes e abrangentes (PRADO FILHO, 2006). Esse sistema de normas configurou também o que vinha sendo instalado como discurso de promoção da saúde, decorrendo aí processos de objetivação, que podem ganhar mais alguma visibilidade nas análises dos seguintes subarquivos.

\section{A busca da institucionalização da promoção da saúde}

Um segundo conjunto de documentos é relativo a publicações nas quais o Ministério da Saúde buscava institucionalizar a promoção da saúde. Esta, ainda que já se fizesse presente no cenário internacional, não teve um lugar de destaque entre discursos que passaram a 
estruturar os documentos legislativos, nos primeiros anos de estabelecimento do SUS, tampouco até então não tinha sido alvo de investimento institucional por meio de outros documentos estatais. Como foi visto, no primeiro subarquivo analisado, a promoção da saúde, a exemplo do conceito de saúde, que ainda era alvo de debates sobre sua definição, foi envolvida pelo conceito de saúde ampliada, que tentava se constituir desviado da doença.

Os documentos a seguir analisados, e que constituem o segundo subarquivo, são resultados de uma articulação da promoção da saúde ao Programa das Nações Unidas para o Desenvolvimento (PNUD), que financiou, em 1998, o projeto intitulado "Promoção da Saúde", ou Projeto BRA 98-006, ou seja, tratava-se de um projeto custeado e formulado por esse organismo internacional, especificamente para o Brasil (BRASIL, 1998). O texto do Projeto BRA 98-006 reitera a Carta de Ottawa (ORGANIZAÇÃO MUNDIAL DA SAÚDE [OMS], 1986) e indica ser necessária "uma ação coordenada entre governo, setor saúde, e outros setores sociais e econômicos, organizações voluntárias e não governamentais, autoridades locais, indústria e mídia”. O projeto resultou em quatro documentos que visavam instalar a promoção da saúde no país, e que constituirão o segundo subarquivo.

Trilhando as séries já anunciadas, na primeira delas "o encampamento pelo Estado", a adoção da promoção da saúde como política ocorre por meio de um discurso imperativo. E, para tanto, os discursos das conferências internacionais de saúde são apresentados em um dos documentos (BRASIL, 2002a), e nos demais são indicadas metodologias por meio das quais o Estado brasileiro deveria encampar a promoção da saúde (BRASIL, 2002b).

Sobre a "gestão em saúde", esses documentos indicam enunciados da Carta de Ottawa (OMS, 1986) que se pautam na intersetorialidade na gestão e na formulação de ambientes favoráveis como projetos a serem desenvolvidos pelo Estado com o intuito de se promover saúde. Contudo, é característica desse conjunto de documentos um desvio da consideração da abrangência dos direcionamentos de Ottawa, ou seja, os documentos não fazem análises mais aprofundadas sobre a realidade canadense [local em que esse documento é formulado] e a brasileira, mas tão somente indicam a busca por cidades saudáveis e o envolvimento de um projeto de país consoante à promoção da saúde (BRASIL, 2002c).

As "condições de saúde e adoecimento da população" também aparecem como preocupação, quando são indicadas situações de risco de adoecimento e ao mesmo tempo hábitos saudáveis, tais como: quantidade de caminhadas para uma pessoa, tipo de alimentos mais adequados, etc. (BRASIL, 2002b, 2002d). Tal tipo de enunciado pode ser visto como empobrecedor de projeto que quis pensar a promoção da saúde, que, como visto antes, envolveria um projeto de país.

Já o risco de adoecimento da população é atrelado ao problema da "saúde e desenvolvimento econômico". Fundamentando o discurso em relatórios sobre a saúde da população mundial, os riscos de adoecer no mundo são ressaltados como risco ao desenvolvimento econômico, social e humano. Nesse sentido, as Doenças Crônicas Não Transmissíveis (DCNT) e maus hábitos de vida são lembrados como custos ao país (BRASIL, 2002c).

Nesse segundo subarquivo, a "participação social" é indicada como condição para se pensar a promoção da saúde. E aqui aparece a promoção da saúde conjugada à ocorrência de um trabalho intersetorial, ou diálogo com "a sociedade, com seus setores produtivos, com suas organizações comunitárias e com seus meios de comunicação para um pacto pela saúde" (BRASIL, 2002b, p. 5). Contudo, mais uma vez, os documentos não fazem qualquer avaliação do controle social e sobre processos de participação que já se encontravam instalados no país. Nessa mesma senda, a "saúde como estratégia para a democracia" também aparece estruturando os discursos dos documentos desse subarquivo, até porque a Reforma do Estado, com base na Constituição, estava levando à descentralização da gestão em saúde e precisava de um elemento organizador da condução da população nos novos direcionamentos administrativos de gestão.

Nesse subarquivo há uma acomodação das práticas de saúde instaladas na década anterior, pós CF/88. Nele fica clara a intervenção internacional na política brasileira, quando o PNUD, com o "Projeto Promoção da saúde", em face da impotência do Brasil em caminhar pari passu à Carta de Ottawa (OMS, 1986), procura instalar no país essa política. Contudo, o projeto do PNUD fica fragmentado e é adiado pelas dificuldades em articular tensões com a biomedicina (CASTRO, 2005). E a promoção da saúde, nesse momento, em face de várias mudanças ministeriais, é direcionada para a "Coordenadoria Geral de Doenças e Agravos Não Transmissíveis "” (CGDANT), na Secretaria de Vigilância e Saúde (SVS), quando a promoção da saúde passa a ser um apêndice do "Seminário Nacional de Vigilância em Doenças e Agravos Não Transmissíveis e Promoção da Saúde".

Nesse subarquivo é possível visualizar a promoção da saúde como um discurso de adequação e instalação de um modelo neoliberal da gestão da vida no país. Ou seja, trata da tentativa de otimização da população por meio de estratégias biológicas, sendo priorizada a gestão de riscos e segurança da população, o que se constitui um grande desvio de Ottawa, porque risco não fazia parte das preocupações daquele documento.

É possível a visibilidade, a partir desse documento, da promoção da saúde como uma biopolítica, cujas práticas de governo conduzem o sujeito para a ideia de que "vive-se perigosamente", ou sob o risco do adoecimento. Contudo, não se trata de uma ideia de risco enquanto prevenção de acidentes ou doenças, mas o risco é colocado na dimensão individual da vida, voltando-se para estilos de vida (CAPONI, 2003). O problema do adoecimento aqui se refere à necessidade de produção de corpos. Seria necessária a regulação de um mercado neoliberal, que se instalava e que tinha como condição para seu funcionamento um homo economicus. Nesse mercado, os sujeitos 
deveriam ser empresários de si mesmo e, desviando-se dos riscos, deveriam, para tanto, estar vivos e produzindo (FOUCAULT, 2008b).

O "Projeto Promoção da Saúde" também foi instalado à margem de debates, sem articulação ao controle social, contribuindo com um esvaziamento dos movimentos sociais. Esse desvio do sujeito coletivo pode ser pensado com efeitos de captura ao individual, quando a promoção da saúde ocorre por meio da afirmação de discursos da corpolatria e higiomania, aos moldes que entendeu Nogueira (2003), por meio da instalação do alarme, que, sem qualquer abertura para saídas do além do modelo médico, fortalece este último.

\section{Estabelecimento da promoção da saúde no Brasil: dispositivo de governo médico da vida}

No terceiro subarquivo pode ser vista uma reorientação da organização do setor saúde por meio do "Pacto pela Saúde", (pela vida, de gestão e em Defesa do SUS) (BRASIL, 2006c). A partir do Pacto é lançada então a Política Nacional de Promoção da Saúde (PNPS) e a Política Nacional de Atenção Básica (PNAB).

$\mathrm{Na}$ série "o encampamento pelo Estado" se torna visível como, a partir do Pacto, há a habilitação dos municípios por regiões enquanto organizadores das necessidades de saúde, comprometendo a gestão para tal. E essa condição busca ser diferente do que vinha sendo empreendido até então, porque com a NOB/1996 não havia esse processo de responsabilização de gestores.

Com o Pacto, muda também o processo de "gestão em saúde", porque localmente se busca a unificação, estabelecimento de metas e monitoramento de projetos locais. Mas com o Pacto se estabeleceu um problema: a promoção da saúde é localizada na atenção básica, mas deveria ser de responsabilidade intersetorial, como já foi indicado antes em Ottawa e no Projeto do PNUD. Diante disso, o que seja promoção da saúde passa a ser pensado alhures à gestão, pois com o Pacto a promoção da saúde deve fazer "dialogar as diversas áreas do setor sanitário, outros setores do governo, os setores privados e não governamental e a sociedade" (BRASIL, 2006a, p. 7). E isso é importante porque a promoção da saúde, em seu planejamento e financiamento, passa a ocorrer fora da atenção básica, ou seja, dentro de setores aos quais ela interessa na sociedade. O que restaria à atenção básica seria o trabalho com adoecimentos?

A resposta à questão anterior é visível na série "as condições de saúde e adoecimento”. O Pacto exclui financiamento para a promoção da saúde e, ao mesmo tempo, passa a definir, para a atenção básica, uma agenda sobre as doenças enfrentadas a cada ano. O financiamento da atenção básica passou a se dar por meio de blocos, que inclui vigilância em saúde e farmácia, inclusive com acréscimos para a atenção básica que tivesse desenvolvido programas específicos para atendimento a diabéticos e hipertensos. Assim, com uma desresponsabilização da gestão pública pela execução da promoção da saúde, o foco no adoecimento ganhou lugar na atenção primária. E, por que não dizer, fora da atenção básica, pois a in- tersetorialidade, em face de um cenário de adoecimentos, poderia estabelecer sua capacidade contributiva com ações relativas a doenças, ainda que sob a égide da promoção da saúde, pois desse modo, em face dos discursos de riscos, suas ações ganhariam mais visibilidade.

Outro conjunto de enunciados ajuda a pensar como a promoção da saúde fora sendo estabelecida até aqui. A série "desenvolvimento econômico" perde força nesse documento e aparece com parcas presenças no Pacto, PNPS e PNAB. A economia aparece até mesmo como consolidada, quando a garantia à saúde é "a formulação de políticas sociais e econômicas que operem na redução dos riscos de adoecer" (BRASIL, 2006a, p. 16).

A "participação social" é considerada nesses documentos, mas o controle social pode ser visto sem potência de deliberação. Isto porque na PNAB a participação é princípio, e não diretamente articulada ao controle social estabelecido. A ESF deveria estimular a "comunidade no controle social, no planejamento, execução e avaliação das ações" (BRASIL, 2006b, p. 28), mas na PNPS a participação fica distante do controle social, pois, como diz o próprio documento, esta "vai além dos modos institucionalizados de controle social, implicando a criação de mecanismos de mobilização e participação" (BRASIL, 2006a, p. 15).

A "saúde como estratégia para a democracia", com o Pacto, assim como a economia, também perde força no discurso. A democracia é apresentada como método de gestão e consolidada na PNPS, pois, "no Brasil, pensar outros caminhos para garantir a saúde da população significou pensar a redemocratização do país e a constituição de um sistema de saúde inclusivo" (BRASIL, 2006a, p. 13).

A instalação da promoção da saúde encontrou nesse conjunto de documentos uma contradição com a concepção de atenção básica. Isto porque se estabeleceu uma marginalidade da potência da atenção básica em desenvolver práticas de promoção da saúde, quando colocada com foco na atenção à doença. Isto leva a promoção da saúde a ser dispositivo que ganha um aliado estratégico: a intersetorialidade. Esta última se constitui espaço para que se recorra diante de problemas.

O Estado, ao delegar à intersetorialidade a implementação da promoção da saúde, possibilita a racionalidade médico-centrada, talvez não nos discursos, mas nas práticas. O governo da vida sobre a população continua por meio de vidas investidas de cima abaixo, com foco primeiro na doença na medida do que seja necessário.

O corpo entra aqui para a história (FOUCAULT, 1988b), descentrado do sujeito e em colaboração com um modelo econômico neoliberal. E nessa mesma linha de despolitização há decorrência para a participação, que não ocorre, mas é mantida por meio de enunciados que não açambarcam a história. Nessa perspectiva, a promoção da saúde, agora em uma relação mais clara com a atenção básica, passa a ser um dispositivo biopolítico de segurança, com a complexidade de ser elástica ao modelo econômico e suas demandas por vida, o que a torna também dispositivo de controle, uma máquina de governo das condutas, cada vez mais fina e subjetivante (PRADO FILHO, 2006). 


\section{Considerações finais}

O objetivo deste estudo foi o de avaliar, a partir do processo de redemocratização do país, a promoção da saúde enquanto discurso e prática que envolve a constituição de sujeitos. A promoção da saúde foi analisada como dispositivo de governo, saberes e práticas, datadas na história, incidindo sobre os sujeitos, objetivando-os, e não enquanto uma prática específica.

Na problematização dos discursos e práticas de promoção da saúde no cenário institucional nacional, a partir dos documentos analisados, foi possível a visualização da promoção da saúde, no fim da década de 1980 e ao longo da década de 1990, entre os discursos da saúde ampliada. Destacadamente na atenção básica, foi possível o encontro de uma promoção da saúde insipiente, como uma reedição do modelo preventivo.

Por volta do ano 2000, a promoção da saúde teve um investimento na tentativa de ser organizada como uma política, mas apenas envolta em um poder médico e na vigilância requisitada pelo neoliberalismo desenvolvimentista. E depois, com a sua instalação propriamente dita, como Política Nacional de Promoção da Saúde, em 2006, a promoção da saúde pode ser vista em meio ao estabelecimento de desvios da doença, coordenada pela intersetorialidade, com um declínio da participação social e marginal à atenção básica.

O percurso da análise dos dados dos documentos permite afirmar que a atenção básica, que seria o lugar de promoção da saúde, não se colocou como alternativa à biomedicina, mas com práticas nela centralizadas. Tal condição conduz para saúde ser "dever do cidadão e um direito do Estado”, tal qual indicado por Schramm (2006, p. 197).

O percurso trilhado, a partir da análise dos três subarquivos, também permitiu visibilidade sobre como práticas biopolíticas, no período da democratização brasileira, movidas pela ideia de promoção da saúde, objetivam sujeitos. A subjetividade, que é histórica (FIGUEIREDO, 1992), tem seu desenho marcado pela biopolítica e governamentalidade. O sujeito é conduzido à ética de excelência, tendo a saúde como norma, sendo conduzido a ser vigilante em face dos riscos anunciados. Desse modo, o sujeito, por meio de sua saúde, pode ser envolto em distanciamentos da dimensão política envolvida.

Ressalte-se que o estudo da dimensão política poderá ser mais bem açambarcado, com maior visibilidade sobre o processo de subjetivação, ou seja, por meio da análise da resistência a esses processos de objetivação, em busca de práticas de liberdade, a partir dos estudos de Foucault (1988b). Tal articulação dar-se-á em continuidade a este estudo, em uma publicação vindoura, que envolverá a articulação com uma prática de promoção da saúde na atenção básica.

A pesquisa aqui empreendida permitiu afirmar o potencial da pesquisa documental em conferir visibilidade sobre fenômenos relativos ao campo da saúde, a partir de discursos incidentes sobre esse campo. Especialmente na pesquisa em saúde, isso pode ser expresso pelo acesso a processos de subjetivação em meio a gama de produções em saúde. Além disso, especificamente diante do objeto de estudo aqui localizado, foi possível ter visibilidade da forma como a saúde ampliada, motor de muitas lutas no campo da saúde, foi sendo edificada, ao longo dos anos, seja no campo dos discursos, seja traduzindo-se em práticas, objetivando sujeitos.

De outro modo, a partir da perspectiva da pesquisa documental, no presente estudo, pôde-se conferir também a grandiosidade da contribuição do pensamento arqueológico empreendido por Foucault (2008a), no texto a Arqueologia do saber, quando abordou os arquivos enquanto monumentos. Seguindo a arqueologia de Foucault (2008a, p. 30), foi possível saber "segundo que regras um enunciado [do campo da saúde] foi construído $\mathrm{e}$, consequentemente, segundo que regras outros enunciados semelhantes poderiam ser construídos" nesse mesmo campo. E, ainda, compreender o enunciado na sua estreiteza, singularidade, condições de existência, limites, e em correlações com outros enunciados; ou seja, o movimento político e histórico colocado pelos enunciados sob estudo. No presente estudo a perspectiva do arquivo possibilitou a visibilidade dos enunciados movimentando acontecimentos que envolveram um período importante da saúde no país, mas não sem envolver a objetivação dos sujeitos.

\section{Informações sobre a autora:}

Ana Maria Pereira Lopes

\section{https://orcid.org/0000-0001-5915-0546}

\section{http://lattes.cnpq.br/9988734902121557}

Possui graduação em Psicologia pela Universidade Federal de Santa Catarina (1994), mestrado em Psicologia pela Universidade Federal de Santa Catarina (2002), com dissertação com temática acerca da saúde mental e trabalho em saúde mental; e doutorado em Programa de Pós-Graduação em Psicologia pela Universidade Federal de Santa Catarina (2012), com tese acerca da promoção da saúde enquanto biopolítica. Atualmente é professor titular da Universidade do Sul de Santa Catarina (UNISUL). Tem experiência na docência em Psicologia, com ênfase na saúde, atuando principalmente nos seguintes temas: atenção básica (saúde mental) e psicologia hospitalar, e com a intersetorialidade a políticas públicas (assistência social, segurança, educação e outras). Tem experiência na temática relativa à organização da profissão de psicólogo e ética profissional. Faz parte do Comitê de Ética em Pesquisa da UNISUL e foi tutora do Programa de Educação para o Trabalho em Saúde (PET) Saúde - Ministério da Saúde.

\section{Como citar este artigo:}

\section{ABNT}

LOPES, Ana Maria Pereira. Promoção da saúde no processo de democratização brasileiro: biopolíticas e constituição de sujeitos da saúde. Fractal: Revista de Psicologia, Niterói, v. 31, n. 3, p. 283 291, set./dez. 2019. https://doi.org/10.22409/1984-0292/v31i3/5509

\section{APA}

LOPES, A. M. P. (2019, Setembro/Dezembro). Promoção da saúde no processo de democratização brasileiro: biopolíticas e constituição de sujeitos da saúde. Fractal: Revista de Psicologia, 31(3), 283-291. doi: https://doi.org/10.22409/1984-0292/v31i3/5509

Fractal, Rev. Psicol., v. 31 - n. 3, p. 283-291, 2019 


\section{Referências}

ALBUQUERQUE JÚNIOR, Durval Muniz. Mennocchio e Rivière: criminosos da palavra, poetas do silencio. Resgate: Revista Interdisciplinar de Cultura do Centro de Memória da Unicamp, Campinas, n. 1, p. 48-55, 1991. Disponível em: https://periodicos.sbu.unicamp.br/ojs/index.php/resgate/ article/view/8645467/12774. Acesso em: 13 ago. 2016.

BRASIL. Ministério da Saúde. Conselho Nacional de Saúde. CONFERÊNCIA NACIONAL DE SAÚDE, 8., 1986, Brasília Anais... Brasília: MS, 1986. Disponível em: http://www.ccs. saude.gov.br/cns/pdfs/8conferencia/8conf_nac_anais.pdf. Acesso em: 27 out. 2017.

BRASIL. Presidência da República. Casa Civil. Subchefia para Assuntos Jurídicos. Constituição da República Federativa do Brasil de 1988. 1988. Disponível em: http:/www.planalto.gov. br/ccivil 03/constituicao/constituicao.htm. Acesso em: 13 ago. 2016.

BRASIL. Presidência da República. Casa Civil. Subchefia para Assuntos Jurídicos. Lei $n^{\circ}$ 8080, de 19 de setembro de 1990. Dispõe sobre as condições para a promoção, proteção e recuperação da saúde, a organização e o funcionamento dos serviços correspondentes e dá outras providências. 1990a. Disponível em: http://www.planalto.gov.br/ccivil_03/leis/ 18080.htm. Acesso em: 14 ago. 2016.

BRASIL. Presidência da República. Casa Civil. Subchefia para Assuntos Jurídicos. Lei $n^{\circ}$ 8142, de 28 de dezembro de 1990. Dispõe sobre a participação da comunidade na gestão do Sistema Único de Saúde (SUS) e sobre as transferências intergovernamentais de recursos financeiros na área da saúde e dá outras providências. 1990b. Disponível em: http://www planalto.gov.br/ccivil_03/leis/L8142.htm. Acesso em: 14 ago. 2016.

BRASIL. Ministério da Saúde. Norma Operacional Básica do Sistema Único de Saúde - SUS 01/96. Brasília: Ministério da Saúde, 1996.

BRASIL. Ministério da Saúde. Secretaria de Assistência à Saúde. Saúde da Família: uma estratégia para a reorientação do modelo assistencial. Brasília: Ministério da Saúde, 1997.

BRASIL. Ministério da Saúde. Promoção da saúde, um novo modelo de atenção: Documento do Projeto do Programa das Nações Unidas para o Desenvolvimento/PNUD. Brasília: Ministério da Saúde, 1998.

BRASIL. Ministério da Saúde. As cartas da promoção da saúde. Brasília: Ministério da Saúde, 2002a.

BRASIL. Ministério da Saúde. A construção de vidas mais saudáveis. Brasília: Ministério da Saúde, 2002b.

BRASIL. Ministério da Saúde. Política Nacional de Promoção da Saúde (documento para discussão). Brasília: Ministério da Saúde, 2002c.

BRASIL. Ministério da Saúde. Vamos promover nossa saúde? Brasília: Ministério da Saúde, 2002d.

BRASIL. Ministério da Saúde. Política Nacional de Promoção da Saúde. Brasília: Ministério da Saúde, 2006a.

BRASIL. Ministério da Saúde. Política Nacional de Atenção Básica. Brasília: Ministério da Saúde. 2006b.

BRASIL. Ministério da Saúde. Diretrizes Operacionais dos Pactos pela Vida, em Defesa do SUS e de Gestão. Brasília: Ministério da Saúde, 2006c.
CAPONI, Sandra. A saúde como abertura ao risco. In: CZERESNIA Dina; FREITAS Carlos Machado de. (Org.). Promoção da saúde: conceitos, reflexões, tendências. Rio de Janeiro: Fiocruz, 2003. p. 39-53.

CASTRO, Adriana Miranda de. A institucionalização da Promoção da Saúde no SUS. Rio de Janeiro: UIPES / ORLA, 2005.

FIGUEIREDO, Luis Cláudio. Matrizes do pensamento psicológico. Petrópolis, RJ: Vozes, 1992.

FOUCAULT, Michel. História da sexualidade: a vontade de saber. Rio de Janeiro: Graal, 1988a. v. 1.

FOUCAULT, Michel. História da sexualidade: o cuidado de si. Rio de Janeiro: Graal, 1988b. v. 3.

FOUCAULT, Michel. Microfisica do poder. Rio de Janeiro: Graal, 1992.

FOUCAULT, Michel. Em defesa da sociedade. São Paulo: Martins Fontes, 1999.

FOUCAULT, Michel. A arqueologia do saber. Rio de Janeiro: Forense Universitária, 2008a.

FOUCAULT, Michel. Nascimento da biopolitica. São Paulo: Martins Fontes, 2008b.

FOUCAULT, Michel. Crise da medicina ou crise da antimedicina. In: MOTTA, Manoel Barros da (Org.). Foucault: arte, epistemologia, filosofia, história da medicina. Rio de Janeiro: Forense Universitária, 2011. Coleção Ditos \& Escritos, v. 7, p. 373-384.

LE GOFF, Jacques. História e memória. 2. ed. Campinas: Unicamp, 1990.

LEMOS, Flavia Cristina Silveira et al. A análise documental como instrumento estratégico para Michel Foucault. In: PIMENTEL, Adelma et al. (Org.). Itinerários de pesquisas em psicologia. Belém: Amazonas, 2010. p. 95-118.

LUZ, Madel Therezinha. Duas questões permanentes em um século de políticas de saúde no Brasil republicano. Ciência \& Saúde Coletiva, Rio de Janeiro, v. 5, n. 2, p. 293-312, 2000. http://dx.doi.org/10.1590/S1413-81232000000200006

MATTOS, Ruben Araujo de. Princípios do Sistema Único de Saúde (SUS) e a humanização das práticas de saúde. Interface (Botucatu), Botucatu, v. 13, supl. 1, p. 771-780, 2009. http:// dx.doi.org/10.1590/S1414-32832009000500028

NOGUEIRA, Roberto Passos. A segunda crítica social da saúde de Ivan Illich. Interface (Botucatu), Botucatu, v. 7, n. 12, p. 185-190, 2003. http://dx.doi.org/10.1590/S141432832003000100022

ORGANIZAÇÃO MUNDIAL DA SAÚDE. Carta de Ottawa. 1986. Disponível em: http://bvsms.saude.gov.br/bvs/ publicacoes/carta_ottawa.pdf. Acesso em: 22 jan. 2016.

PRADO FILHO, Kleber. Michel Foucault: uma história da governamentalidade. Rio de Janeiro: Insular; Achiamé, 2006.

SCHRAMM, Roland Fermin. A saúde é um direito ou um dever? Uma autocrítica da saúde pública. Revista Brasileira de Bioética, Brasília, v. 2, n. 2, p. 187-200, 2006. 